\title{
Energy expenditure in critically ill patients estimated by population-based equations, indirect calorimetry and $\mathrm{CO}_{2}$-based indirect calorimetry
}

Mark Lillelund Rousing ${ }^{1 *}$, Mie Hviid Hahn-Pedersen ${ }^{1}$, Steen Andreassen ${ }^{1}$, Ulrike Pielmeier ${ }^{1}$ and Jean-Charles Preiser ${ }^{2}$

\begin{abstract}
Background: Indirect calorimetry $(\mathrm{IC})$ is the reference method for measurement of energy expenditure (EE) in mechanically ventilated critically ill patients. When IC is unavailable, EE can be calculated by predictive equations or by $\mathrm{VCO}_{2}$-based calorimetry. This study compares the bias, quality and accuracy of these methods.

Methods: EE was determined by IC over a 30-min period in patients from a mixed medical/postsurgical intensive care unit and compared to seven predictive equations and to $\mathrm{VCO}_{2}$-based calorimetry. The bias was described by the mean difference between predicted $E E$ and IC, the quality by the root mean square error (RMSE) of the difference and the accuracy by the number of patients with estimates within $10 \%$ of IC. Errors of $\mathrm{VCO}_{2}$-based calorimetry due to choice of respiratory quotient $(\mathrm{RQ})$ were determined by a sensitivity analysis, and errors due to fluctuations in ventilation were explored by a qualitative analysis.

Results: In 18 patients (mean age $61 \pm 17$ years, five women), EE averaged $2347 \mathrm{kcal} /$ day. All predictive equations were accurate in less than $50 \%$ of the patients with an RMSE $\geq 15 \% . \mathrm{VCO}_{2}$-based calorimetry was accurate in $89 \%$ of patients, significantly better than all predictive equations, and remained better for any choice of $\mathrm{RQ}$ within published range (0.76-0.89). Errors due to fluctuations in ventilation are about equal in $\mathrm{IC}$ and $\mathrm{VCO}_{2}$-based calorimetry, and filtering reduced these errors.
\end{abstract}

Conclusions: This study confirmed the inaccuracy of predictive equations and established $\mathrm{VCO}_{2}$-based calorimetry as a more accurate alternative. Both $\mathrm{IC}$ and $\mathrm{VCO}_{2}$-based calorimetry are sensitive to fluctuations in respiration.

Keywords: Energy expenditure, Metabolic rate, Caloric intake, Nutritional support, Critically ill, Indirect calorimetry, Respiratory quotient, $\mathrm{VCO}_{2}$

\section{Background}

The determination of energy expenditure (EE) can help clinicians to prescribe caloric intake during the late phase of critical illness, particularly in obese, cachectic or burned patients [1]. The reference method to determine

\footnotetext{
*Correspondence: mlr@hst.aau.dk

${ }^{1}$ Center for Model-based Medical Decision Support (MMDS), Department of Health Science and Technology, Aalborg University, Fredrik Bajers Vej 7E, 9220 Aalborg East, Denmark

Full list of author information is available at the end of the article
}

EE is indirect calorimetry (IC) [2], which uses the Weir equation [3] to provide an estimate of EE from measured oxygen consumption $\left(\mathrm{VO}_{2}\right)$ and carbon dioxide production $\left(\mathrm{VCO}_{2}\right)$. However, the use of IC is limited by the associated costs, necessary training and demand on resources (e.g., time, equipment and staff) $[4,5]$. Furthermore, IC measurements may not be feasible because of logistic or technical difficulties, in about $35-40 \%$ of patients even under conditions of a clinical prospective trial $[6,7]$. 
Regardless of the nutritional target, relative to EE, for a patient, EE should be accurately determined. The use of EE determined by predictive equations is recommended when IC cannot be used. For instance, the American College of Chest Physicians (ACCP) equation [8] uses body mass $(\mathrm{BM})$ as the only variable describing the patient: $\mathrm{EE}(\mathrm{ACCP})=(25-30 \mathrm{kcal} / \mathrm{kg} /$ day $\cdot \mathrm{BM})$. European [9] and Canadian [10] guidelines concur and both recommend a target of 20-25 kcal $/ \mathrm{kg} /$ day. Other equations also use the patient's height and age and gender (Harris-Benedict [11] and Mifflin St Jeor [12]). The Penn State equations $[13,14]$ add respiratory minute volume (MV) and body temperature to further describe the state of the patient.

Reviews by Tatucu-Babet et al. [6] and Frankenfield et al. [15] of the extensive body of the literature on predictive equations conclude that they often are inaccurate. Both reviews used a $\pm 10 \%$ difference between the predictive equations and IC to assess over- or underestimations of EE. Frankenfield et al. [15] found that the four equations reviewed all had over- and/or underestimations larger than $10 \%$ in at least $18 \%$ of the patients. Tatucu-Babet et al. [6] found that $12 \%$ of the reviewed predictive equations on average over the patient group studied overestimated EE by more than $10 \%$ and up to $66 \%$ in individual patients. Underestimation was even more frequent with $38 \%$ of the equations underestimating EE by more than $10 \%$ and up to $41 \%$ in individual patients. The frequent underestimations were partially compensated for by multiplying the EE estimated by the predictive equations by a stress factor (SF) and most of the studies evaluating the Harris-Benedict equation used a SF, which ranged from 1.13 to 1.6. This large range of SF may partially be due to interpatient differences, but also to systematic variations of SF due to the severity and type (sepsis, trauma/surgery, burns) of insult [16-18] as well as the time elapsed since the insult $[16,17]$. The value of SF is therefore cohort specific, depending on both patient mix and other clinical circumstances.

An alternative may be " $\mathrm{VCO}_{2}$-based calorimetry" where $\mathrm{EE}$ is calculated only from $\mathrm{VCO}_{2}$, routinely measured by capnometers connected to the ventilatory circuit in mechanically ventilated patients [19]. In this paper, we investigate a method to calculate the $\mathrm{VCO}_{2}$-based $\mathrm{EE}$ from a modified Weir equation [3]: $\mathrm{EE}\left(\mathrm{VCO}_{2}\right)=\left(\left(5.5 \mathrm{~min} / \mathrm{ml} \cdot \mathrm{RQ}^{-1}+1.76 \mathrm{~min} /\right.\right.$ $\left.\mathrm{ml}) \cdot \mathrm{VCO}_{2}-26\right) \mathrm{kcal} /$ day [20]. In a clinical application of $\mathrm{VCO}_{2}$-based calorimetry where $\mathrm{VO}_{2}$ is not measured, the respiratory quotient (RQ) for the individual patient is unknown and a value of RQ for the individual patient must therefore be chosen. This value may be set to the average from a patient cohort $[20,21]$ or can be individualized by calculating it from the patient's nutrition
$[22,23]$. The purpose of this study is to determine the accuracy of $\mathrm{VCO}_{2}$-based calorimetry using the modified Weir equation stated above compared with the accuracy of commonly used predictive equations for EE, using IC as the reference method. In clinical practice, the $\mathrm{VCO}_{2}$ measurements are presumably taken using the ventilator's capnometer. The scope of this paper is not the potential discrepancy between $\mathrm{VCO}_{2}$ measurements from capnometers in metabolic monitors and in ventilators, but only the accuracy of the $\mathrm{VCO}_{2}$-based calorimetry compared with IC. Possible sources of error in the $\mathrm{VCO}_{2}$-based calorimetry and $\mathrm{IC}$ will be assessed by a qualitative analysis of data, including a sensitivity analysis of the choice of RQ value.

\section{Methods}

\section{Patients}

An observational trial was conducted at a mixed medical/postsurgical intensive care unit (ICU) at Erasme University Hospital of Brussels, Belgium. No ethics committee approval was necessary as only noninvasive and anonymized data were collected. Eighteen patients 18 years or older were included as soon as possible after ICU admission, if they were intubated and mechanically ventilated. Height, gender, body mass, temperature, diagnosis, mode of ventilation, APACHE 2 score at admission [24], and sedation were recorded. $\mathrm{VO}_{2}, \mathrm{VCO}_{2}$, end-tidal $\mathrm{CO}_{2}\left(\mathrm{ET}-\mathrm{CO}_{2}\right), \mathrm{FiO}_{2}, \mathrm{MV}$ and RQ were measured over a 30-min period. The metabolic monitor used was a Compact Airway Module, E-CAiOVX, mounted in a Compact Anesthesia Monitor (GE Healthcare, Little Chalfont, Buckinghamshire, UK), which offers continual $\mathrm{VCO}_{2}$ and $\mathrm{VO}_{2}$ measurements [25]. The Compact Airway Module determines $\mathrm{VCO}_{2}$ and $\mathrm{VO}_{2}$ within $\pm 10 \%$ when $\mathrm{FiO}_{2}<65 \%$ [26].

EE is determined, using the Weir Eq. (3):

$$
\begin{aligned}
\mathrm{EE}(\mathrm{IC})= & \left(5.5 \mathrm{~min} / \mathrm{ml} \cdot \mathrm{VO}_{2}+1.76 \mathrm{~min} / \mathrm{ml} \cdot \mathrm{VCO}_{2}\right. \\
& -1.99 \mathrm{day} / \mathrm{g} \cdot \mathrm{N}) \mathrm{kcal} / \text { day }
\end{aligned}
$$

with a standard setting of $N=13 \mathrm{~g} /$ day [26], as ureic nitrogen was not measured in the study, yielding:

$$
\begin{aligned}
\mathrm{EE}(\mathrm{IC})= & \left(5.5 \mathrm{~min} / \mathrm{ml} \cdot \mathrm{VO}_{2}\right. \\
& \left.+1.76 \mathrm{~min} / \mathrm{ml} \cdot \mathrm{VCO}_{2}-26\right) \mathrm{kcal} / \text { day }
\end{aligned}
$$

In this study, this is used as the reference method, against which other EE estimates are compared.

\section{Equations for estimation of $\mathrm{EE}$}

The equation for estimating $\mathrm{EE}$ based on $\mathrm{VCO}_{2}$ was constructed from Eq. 2, with $\mathrm{VO}_{2}$ substituted by:

$$
\mathrm{VO}_{2}=\mathrm{VCO}_{2} / \mathrm{RQ}
$$


This gives the modified Weir equation:

$$
\begin{aligned}
\mathrm{EE}\left(\mathrm{VCO}_{2}\right)= & \left(\left(5.5 \mathrm{~min} / \mathrm{ml} \cdot \mathrm{RQ}^{-1}+1.76 \mathrm{~min} / \mathrm{ml}\right)\right. \\
& \left.\cdot \mathrm{VCO}_{2}-26\right) \mathrm{kcal} / \text { day }
\end{aligned}
$$

$\mathrm{VCO}_{2}$ measurements used in the $\mathrm{EE}(\mathrm{IC})$ and $\mathrm{EE}\left(\mathrm{VCO}_{2}\right)$ estimations are both derived from the metabolic monitor. Differences between $\mathrm{EE}(\mathrm{IC})$ and $\mathrm{EE}\left(\mathrm{VCO}_{2}\right)$ must be either due to an incorrect assumption about RQ or due to variations in ventilation. Variations in ventilation will cause different variations in $\mathrm{EE}(\mathrm{IC})$ and $\mathrm{EE}\left(\mathrm{VCO}_{2}\right)$ because the time constant for $\mathrm{VCO}_{2}$ equilibration is much longer (10-20 $\mathrm{min})[27,28]$ than the time constant for $\mathrm{VO}_{2}$ equilibration (2-3 min) [29].

The accuracy of the $\mathrm{EE}\left(\mathrm{VCO}_{2}\right)$ estimates and that of some commonly used predictive equations (Table 1 ) were compared to EE(IC).

The cohort-specific value of SF for the Harris-Benedict equation (b, Table 1 ) was calculated using the following equation:

$$
\mathrm{SF}=\text { mean } \mathrm{EE}(\mathrm{IC}) / \text { mean } \mathrm{EE}(\mathrm{HB})
$$

The SF for methods $\mathrm{c}$ and $\mathrm{d}$ (Table 1) were similarly determined using their respective mean EE. The result is that the mean $E E$ for the 18 patients determined by each method equals the mean EE(IC) determined by Eq. 2 (the reference method).

The ideal body mass (IBM) was calculated from the Hamwi equations [31]:

$$
\begin{aligned}
\text { Men: IBM }= & 48.0 \mathrm{~kg}+2.7 \mathrm{~kg} \cdot(\text { height } \\
& -1.524 \mathrm{~m}) / 0.0254 \mathrm{~m}
\end{aligned}
$$

$$
\text { Women: } \begin{aligned}
\mathrm{IBM}= & 45.5 \mathrm{~kg}+2.2 \mathrm{~kg} \cdot(\text { height } \\
& -1.524 \mathrm{~m}) / 0.0254 \mathrm{~m}
\end{aligned}
$$

\section{Sensitivity analysis of $\mathrm{RQ}$}

The practical use of $\mathrm{VCO}_{2}$-based calorimetry relies on a choice of RQ. A sensitivity study of the effect of the choice of RQ will be conducted. In six studies [14, $18,32-36]$, the average reported cohort values for RQ ranged from 0.76 to 0.89 . These minimum and maximum values and the extreme range of the physiological range $(0.7-1.0)$ [23] will be used in the sensitivity analysis.

\section{Statistical analysis \\ Over-/underestimation}

The bias of each method [the predictive equations and $\left.\mathrm{EE}\left(\mathrm{VCO}_{2}\right)\right]$ was expressed by the difference in percent between mean EE for the method and mean EE(IC). The significance was tested by a two-tailed paired $t$ test. The assumption of normal distribution of tested variables was assessed with the Shapiro-Wilk test.

\section{Quality}

The root mean square error (RMSE) was used to describe the quality of the predictions for each method. A comparison of $\mathrm{EE}\left(\mathrm{VCO}_{2}\right)$ and each predictive equation was

\begin{tabular}{|c|c|c|}
\hline Method & & Equation \\
\hline \multirow[t]{2}{*}{ a } & ACCP & The ACCP equation $[9,10,30]$ using $\mathrm{BM}$ as the only variable \\
\hline & & $\mathrm{EE}(\mathrm{ACCP})=25 \mathrm{kcal} / \mathrm{kg} / \mathrm{day} \cdot \mathrm{BM}$ \\
\hline \multirow[t]{2}{*}{ b } & Harris-Benedict & The Harris-Benedict equation from 1919 [11] multiplied by a SF \\
\hline & & $\begin{array}{l}\text { Men: } \mathrm{EE}(\mathrm{HB})=\left(66.5+13.75 \mathrm{~kg}^{-1} \cdot \mathrm{BM}+5.003 \mathrm{~cm}^{-1} \cdot \text { height }-6.775 \mathrm{year}^{-1} \cdot \mathrm{age}\right) \mathrm{kcal} / \mathrm{day} \cdot \mathrm{SF} \\
\text { Women: } \mathrm{EE}(\mathrm{HB})=\left(655.1+9.563 \mathrm{~kg}^{-1} \cdot \mathrm{BM}+1.85 \mathrm{~cm}^{-1} \cdot \text { height }-4.676 \mathrm{year}^{-1} \cdot \text { age }\right) \mathrm{kcal} / \mathrm{day} \cdot \mathrm{SF}\end{array}$ \\
\hline \multirow[t]{2}{*}{ c } & Harris-Benedict IBM & The Harris-Benedict equation with ideal body mass (IBM) multiplied by a SF \\
\hline & & $\begin{array}{l}\text { Men: } \mathrm{EE}(\mathrm{HBI})=\left(66.5+13.75 \mathrm{~kg}^{-1} \cdot \mathrm{IBM}+5.003 \mathrm{~cm}^{-1} \cdot \text { height }-6.775 \mathrm{year}^{-1} \cdot \text { age }\right) \mathrm{kcal} / \text { day } \cdot \mathrm{SF} \\
\text { Women: } \mathrm{EE}(\mathrm{HBI})=\left(655.1+9.563 \mathrm{~kg}^{-1} \cdot \operatorname{IBM}+1.85 \mathrm{~cm}^{-1} \cdot \text { height }-4.676 \mathrm{year}^{-1} \cdot \text { age }\right) \mathrm{kcal} / \text { day } \cdot \mathrm{SF}\end{array}$ \\
\hline \multirow[t]{2}{*}{$d$} & Mifflin St Jeor & The Mifflin St Jeor equation [12] multiplied by a SF \\
\hline & & $\begin{array}{l}\text { Men: } \mathrm{EE}(\mathrm{MSJ})=\left(9.99 \mathrm{~kg}^{-1} \cdot \mathrm{BM}+6.25 \mathrm{~cm}^{-1} \cdot \text { height }-4.92 \mathrm{year}^{-1} \cdot \text { age }+166\right) \mathrm{kcal} / \mathrm{day} \cdot \mathrm{SF} \\
\text { Women: } \mathrm{EE}(\mathrm{MSJ})=\left(9.99 \mathrm{~kg}^{-1} \cdot \mathrm{BM}+6.25 \mathrm{~cm}^{-1} \cdot \text { height }-4.92 \mathrm{year}^{-1} \cdot \text { age }-161\right) \mathrm{kcal} / \mathrm{day} \cdot \mathrm{SF}\end{array}$ \\
\hline \multirow[t]{2}{*}{ e } & Penn State 1 & The original Penn State equation from 1998 [13] \\
\hline & & $\mathrm{EE}(\mathrm{PS} 1)=1.1 \cdot \mathrm{HB}+\left(32 \mathrm{~min} \mathrm{I}^{-1} \cdot \mathrm{MV}+140^{\circ} \mathrm{C}^{-1} \cdot \mathrm{T}_{\mathrm{Max}}-5340\right) \mathrm{kcal} / \mathrm{day}$ \\
\hline \multirow[t]{2}{*}{ f } & Penn State 2 & Version 2 of the Penn State equation from 2003 [14] \\
\hline & & $\mathrm{EE}(\mathrm{PS} 2)=0.85 \cdot \mathrm{HB}+\left(33 \mathrm{~min} \mathrm{I}^{-1} \cdot \mathrm{MV}+175^{\circ} \mathrm{C}^{-1} \cdot T_{\mathrm{Max}}-6433\right) \mathrm{kcal} /$ day \\
\hline \multirow[t]{2}{*}{ g } & Penn State 3 & Version 3 of the Penn State equation from 2003 [14] \\
\hline & & $\mathrm{EE}(\mathrm{PS} 3)=0.96 \cdot \mathrm{MSJ}+\left(31 \mathrm{~min} \mathrm{I}^{-1} \cdot \mathrm{MV}+167^{\circ} \mathrm{C}^{-1} \cdot T_{\mathrm{Max}}-6212\right) \mathrm{kcal} /$ day \\
\hline
\end{tabular}
performed by an $F$ test over the prediction errors relative to $\mathrm{EE}(\mathrm{IC})$.

\section{Accuracy}

Per-patient EE estimates were defined as accurate if the estimate was within $\pm 10 \%$ of the IC measurement. The

Table 1 Predictive equations for estimation of EE 
number of patients with accurate predictions was compared between $\mathrm{EE}\left(\mathrm{VCO}_{2}\right)$ and each predictive equation using Fisher's exact test.

Significance level for all tests was $p<0.05$. SPSS version 23 was used for statistical analyses.

\section{Qualitative analysis of dynamic errors}

Both IC and $\mathrm{VCO}_{2}$-based calorimetry rely on the assumption that the rate of ventilated $\mathrm{O}_{2}$ and $\mathrm{CO}_{2}$ is reflecting the rate of $\mathrm{O}_{2}$ consumption and $\mathrm{CO}_{2}$ production, respectively. However, $\mathrm{EE}(\mathrm{IC})$ and $\mathrm{EE}\left(\mathrm{VCO}_{2}\right)$ calculated from instantaneous values of $\mathrm{VO}_{2}$ and $\mathrm{VCO}_{2}$ may be erroneous in situations where respiratory $\mathrm{VO}_{2}$ and $\mathrm{VCO}_{2}$ are not equal to the metabolically consumed or produced $\mathrm{VO}_{2}$ and $\mathrm{VCO}_{2}$, respectively. This may occur when the patient's metabolism changes rapidly, or due to external changes to the patient's ventilation. Patients were divided into a group with varying $\mathrm{EE}$ and a group with constant EE, according to the method described below. For a patient in each group, a descriptive analysis of the reasons for errors was performed by inspection of the 30-min recordings of $\mathrm{MV}, \mathrm{VCO}_{2}, \mathrm{VO}_{2}$ and ET- $\mathrm{CO}_{2}$ and comparing these to the changes in $\mathrm{EE}(\mathrm{IC})$ and $\mathrm{EE}\left(\mathrm{VCO}_{2}\right)$.

\section{Quantitative analysis of dynamic errors}

The effects of changes in ventilation were analyzed for both $\mathrm{EE}(\mathrm{IC})$ and $\mathrm{EE}\left(\mathrm{VCO}_{2}\right)$ to compare the two methods' vulnerability to changes in ventilation. For each patient, the maximum deviation of EE from the mean EE was calculated for both $\mathrm{EE}(\mathrm{IC})$ and $\mathrm{EE}\left(\mathrm{VCO}_{2}\right)$. The effect of a 5-min moving average on the calculated EE was explored by comparing the maximum EE deviations from mean $\mathrm{EE}$, for both $\mathrm{EE}(\mathrm{IC})$ and $\mathrm{EE}\left(\mathrm{VCO}_{2}\right)$, before and after its application.

Method for assessing constancy of EE in individual patients Each patient was analyzed for changes in EE during the 30-min recording period. The chosen marker for this analysis was $\mathrm{VO}_{2}$. $\mathrm{EE}(\mathrm{IC})$ is reliant on $\mathrm{VCO}_{2}$, and $\mathrm{VCO}_{2}$ takes 10-20 min to reach steady state following a change in ventilation pattern $[27,28]$, which implies that $\mathrm{VCO}_{2}$ and therefore also $\mathrm{EE}(\mathrm{IC})$ may not reflect the metabolically produced $\mathrm{VCO}_{2}$ for up to $20 \mathrm{~min}$. Thus, both $\mathrm{EE}$ (IC) and $\mathrm{VCO}_{2}$ are unsuitable as markers for this analysis. $\mathrm{VO}_{2}$, however, reaches steady state after 2-3 min [29], implying that metabolic consumption of $\mathrm{VO}_{2}$ is equal to $\mathrm{VO}_{2}$ removed from inspired air. As this is a short period, compared with the 30 -min recording period, $\mathrm{VO}_{2}$ was chosen as a metabolic marker for constant EE.

For each patient, the trend line for the $\mathrm{VO}_{2}$ recording was compared with the average $\mathrm{VO}_{2}$ over the recording period. If the difference between the trend line and the average was less than $10 \%$ of the average $\mathrm{VO}_{2}$, the patient was considered to have constant EE throughout the recording period.

\section{Results}

\section{Comparing estimates of energy expenditure}

Eighteen patients (mean age $61 \pm 17$ years, five women) were included. Average $\mathrm{VO}_{2}$ for the 18 patients was $343 \pm 77 \mathrm{ml} / \mathrm{min}$ and average $\mathrm{VCO}_{2}$ was $273 \pm 63 \mathrm{ml} /$ min, giving an average RQ of 0.81 . The mean $\mathrm{FiO}_{2}$ was $42 \%$ with no patient exceeding $50 \%$. All patients received intravenous glucose during the measurement period, and patients $1,2,3,14,17$ and 18 received enteral nutrition. The mean RQ for the patients receiving enteral nutrition (0.86) was significantly higher $(p<0.05$; $t$ test, unpaired, two-tailed) than the mean RQ (0.79) for the patients not receiving enteral nutrition. Individual patient characteristics are given in Table 2.

In summary, all predictive equations, a through $\mathrm{g}$, largely over- and underestimated the reference EE value. The bias was the highest for the Penn State equations and the ACCP, while the ranges of estimation difference were largest for the ACCP, Harris-Benedict and Mifflin St Jeor equations (Table 3). The use of SF in the Harris-Benedict and Mifflin St Jeor equations resulted in these equations having a bias of $0 \%$; however, the quality of prediction was poor for all predictive equations, as reflected by a RMSE of $15 \%$ or greater. Finally, the accuracy was also very poor for all predictive equations, with $50 \%$ or less of patients having accurate EE estimates (Fig. 1).

The $\mathrm{EE}\left(\mathrm{VCO}_{2}\right)$ was significantly better than the predictive equations with a low and acceptable bias. The mean $\mathrm{EE}\left(\mathrm{VCO}_{2}\right)$, with an RQ value of 0.81 , was not significantly different from mean $\mathrm{EE}(\mathrm{IC})$, and the $\mathrm{EE}\left(\mathrm{VCO}_{2}\right)$ had a good quality of prediction with an RMSE of $7 \%$. The $\mathrm{EE}\left(\mathrm{VCO}_{2}\right)$ was accurate in $89 \%$ of the patients, significantly better than the predictive equations. It also had the narrower range of estimation differences (Fig. 1).

\section{Sensitivity analysis of RQ}

The sensitivity analysis showed that as long as the RQ is chosen within the published range of average cohort values, 0.76-0.89, the $\mathrm{VCO}_{2}$-based calorimetry performs better than the predictive equations.

\section{Analysis of dynamic errors in $\mathrm{EE}(\mathrm{IC})$ and $\mathrm{EE}\left(\mathrm{VCO}_{2}\right)$}

As explained earlier, changes in ventilation or rapid changes in patient metabolism can be causes of error in EE estimation. These errors will be described qualitatively and quantitatively. 


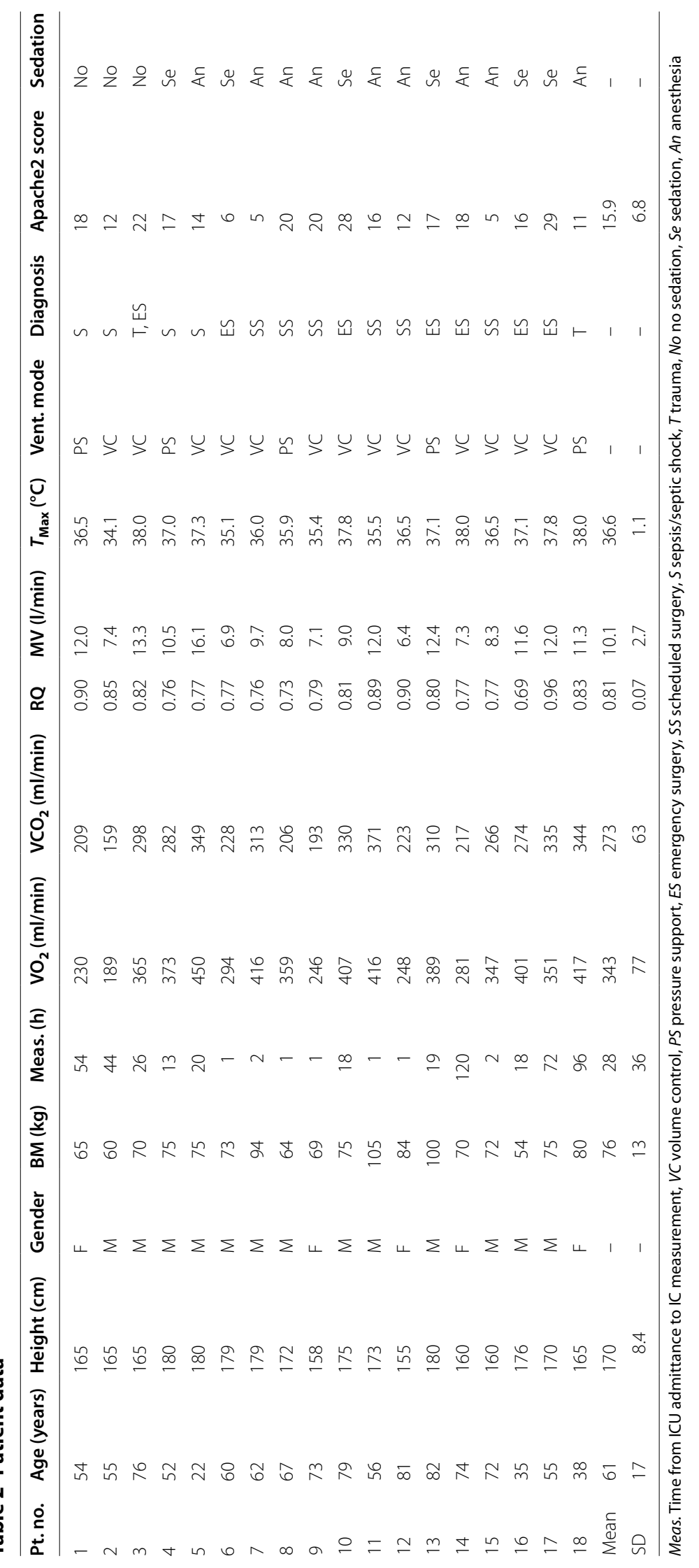


Table 3 Comparison of EE estimates to IC including sensitivity of $\mathrm{EE}\left(\mathrm{VCO}_{2}\right)$ reliance on $\mathrm{RQ}$

\begin{tabular}{|c|c|c|c|c|c|}
\hline Equation & $\begin{array}{l}\text { Mean EE (bias) } \\
\text { (kcal/day) }\end{array}$ & SF & $\begin{array}{l}\text { Range of } \\
\text { estimation } \\
\text { differences }\end{array}$ & $\begin{array}{l}\text { RMSE of EE } \\
\text { difference }\end{array}$ & $\begin{array}{l}\text { \# Of patients } \\
\text { with accurate EE } \\
\text { estimates (\%) }\end{array}$ \\
\hline ACCP & $1889(-20 \%)^{*}$ & NA & [-49\%; $22 \%]$ & $28 \%^{\dagger}$ & $6(33 \%)^{\ddagger}$ \\
\hline Harris-Benedict & 2347 (0 \%) & 1.55 & {$[-20 \% ; 61 \%]$} & $16 \%^{\dagger}$ & $9(50 \%)^{\ddagger}$ \\
\hline Harris-Benedict, IBM & $2347(0 \%)$ & 1.67 & [-23\%; $76 \%]$ & $18 \%^{\dagger}$ & $8(35 \%)^{\ddagger}$ \\
\hline Mifflin St Jeor & $2347(0 \%)$ & 1.59 & {$[-18 \% ; 68 \%]$} & $15 \%^{\dagger}$ & $9(50 \%)^{\ddagger}$ \\
\hline Penn State 1 & $1782(-24 \%)^{*}$ & NA & [-41\%; $0 \%]$ & $27 \%^{\dagger}$ & $1(6 \%)^{\ddagger}$ \\
\hline Penn State 2 & $1572(-33 \%)^{*}$ & NA & {$[-49 \% ;-10 \%]$} & $35 \%^{\dagger}$ & $1(6 \%)^{\ddagger}$ \\
\hline Penn State 3 & $1637(-30 \%)^{*}$ & NA & {$[-43 \% ;-9 \%]$} & $32 \%^{+}$ & $1(6 \%)^{\ddagger}$ \\
\hline $\mathrm{EE}\left(\mathrm{VCO}_{2}\right) \mathrm{RQ}=0.81$ & $2332(-1 \%)$ & NA & {$[-13 \% ; 14 \%]$} & $7 \%$ & $16(89 \%)$ \\
\hline $\mathrm{EE}(\mathrm{IC})$ & $2347(0 \%)$ & NA & - & - & - \\
\hline \multicolumn{6}{|l|}{ Sensitivity analysis of RQ } \\
\hline $\left.\mathrm{EE}(\mathrm{VCO})_{2}\right) \mathrm{RQ}=0.70$ & $2626(12 \%)^{*}$ & NA & {$[-2 \% ; 30 \%]$} & $12 \%$ & $9(50 \%)^{\ddagger}$ \\
\hline $\mathrm{EE}\left(\mathrm{VCO} \mathrm{CO}_{2}\right) \mathrm{RQ}=0.76$ & $2455(5 \%)^{*}$ & NA & [-8\%; $20 \%]$ & $8 \%$ & $14(78 \%)$ \\
\hline $\mathrm{EE}\left(\mathrm{V} C \mathrm{CO}_{2}\right) \mathrm{RQ}=0.85$ & $2244(-4 \%)$ & NA & {$[-16 \% ; 10 \%]$} & $6 \%$ & $16(89 \%)$ \\
\hline $\mathrm{EE}\left(\mathrm{V} C \mathrm{CO}_{2}\right) \mathrm{RQ}=0.89$ & $2163(-8 \%)^{*}$ & NA & {$[-19 \% ; 6 \%]$} & $10 \%$ & $10(56 \%)$ \\
\hline $\mathrm{EE}\left(\mathrm{V} C \mathrm{CO}_{2}\right) \mathrm{RQ}=1.00$ & $1976(-16 \%)^{*}$ & NA & {$[-26 \% ;-3 \%]$} & $17 \%$ & $4(22 \%)^{\ddagger}$ \\
\hline
\end{tabular}

The bias in percent is relative to the mean $\mathrm{EE}(\mathrm{IC})$. The range of estimation differences is the maximum and minimum difference between the equations and individual mean $\mathrm{EE}(\mathrm{IC})$. The RMSE of EE difference is the root mean square error of EE difference between the equations and the IC measurements. Accurate $\mathrm{EE}$ estimates are defined as per-patient mean $\mathrm{EE}$ within $\pm 10 \%$ of $\mathrm{EE}(\mathrm{IC})$

* Significantly different from mean $\mathrm{EE}(\mathrm{IC})$

$\dagger$ Significantly greater variance than $\mathrm{EE}\left(\mathrm{VCO}_{2}\right) \mathrm{RQ}=0.81$

₹ Significantly different from $\mathrm{EE}\left(\mathrm{VCO}_{2}\right) \mathrm{RQ}=0.81$

\section{Checking for constant EE}

Out of the 18 patients, 17 were determined to have constant EE during the 30-min recording period, as the difference between $\mathrm{VO}_{2}$ trend line and mean was less than $10 \%$. For patients $1-17$, the maximal deviation of the trend line from the mean was between 0.9 and $8 \%$. Only patient 18 had a major increase in metabolism with the $\mathrm{VO}_{2}$ trend line deviating $39 \%$ from the mean.

\section{Dynamic errors in patients with variable EE}

Figure 2a shows that for patient 18 the $\mathrm{MV}, \mathrm{VO}_{2}$ and $\mathrm{VCO}_{2}$ are almost constant until 16 min where the patient apparently is aroused and all three parameters rise. $\mathrm{VO}_{2}$ increases by $78 \%$ from $320 \mathrm{ml} / \mathrm{min}$ to about $570 \mathrm{ml} / \mathrm{min}$ and remains increased for over $10 \mathrm{~min}$. If the increase had been due to the increased MV, without any increase in metabolism, then $\mathrm{VO}_{2}$ would have returned to its initial value of about $320 \mathrm{ml} / \mathrm{min}$ within $2-3 \mathrm{~min}$. Since this does not happen, the prolonged increase in $\mathrm{VO}_{2}$ must therefore reflect an increase in metabolism.

Figure $2 \mathrm{~b}$ shows that both $\mathrm{EE}(\mathrm{IC})$ and $\mathrm{EE}\left(\mathrm{VCO}_{2}\right)$, calculated from the recorded $\mathrm{VO}_{2}$ and $\mathrm{VCO}_{2}$, indicate increased $\mathrm{EE}$, approximately to the same degree and simultaneously.

\section{Dynamic errors in patients with constant $E E$}

Most of the 17 patients with constant metabolism had one or more changes of ventilation. Patient 16, whose
$\mathrm{VO}_{2}$ trend line deviated $2.7 \%$ from the mean $\mathrm{VO}_{2}$, will be used as an example. The patient, who was volume controlled, had two changes in ventilation (Fig. 3a): a 3-min period of unstable MV from 7.5 to $10.5 \mathrm{~min}$ and a sustained reduction in MV from 10 min until the end of the recording.

During the unstable period, MV reached a peak value which is $36 \%$ higher than the steady-state value up to $7.5 \mathrm{~min}$. This gave rise to increases in $\mathrm{VO}_{2}$ and $\mathrm{VCO}_{2}$ of 22 and $34 \%$, respectively, which were mirrored as increases in $\mathrm{EE}(\mathrm{IC})$ and $\mathrm{EE}\left(\mathrm{VCO}_{2}\right)$ of about the same size, 24 and $35 \%$, respectively (Fig. $3 \mathrm{~b}$ ).

The second change in ventilation was a sustained reduction in $\mathrm{MV}$ at $10.5 \mathrm{~min}$ from 13.5 to $11.7 \mathrm{l} / \mathrm{min}$. As a result of the reduced ventilation, $\mathrm{ET}-\mathrm{CO}_{2}$ rises, but does not quite reach steady state, because of its 10 - to 20-min equilibration time constant. For the same reason, $\mathrm{VCO}_{2}$ remains low, but rises slowly from $10.5 \mathrm{~min}$ and on. In contrast to $\mathrm{VCO}_{2}, \mathrm{VO}_{2}$ equilibrates within a few minutes and returns to its original value of about $400 \mathrm{ml} / \mathrm{min}$, indicating that there is no reason to suspect that the patient's EE changes during the 10 -min period shown in Fig. 3. Therefore, the fluctuations of EE(IC) and $\mathrm{EE}\left(\mathrm{VCO}_{2}\right)$ must be ascribed to the fluctuations of $\mathrm{MV}$.

The changes in $\mathrm{VO}_{2}$ and $\mathrm{VCO}_{2}$ are reflected in the changes in $\mathrm{EE}(\mathrm{IC})$ and $\mathrm{EE}\left(\mathrm{VCO}_{2}\right)$ (Fig. 3b). At $12.5 \mathrm{~min}$, $\mathrm{EE}(\mathrm{IC})$ has almost recovered and reached its original 


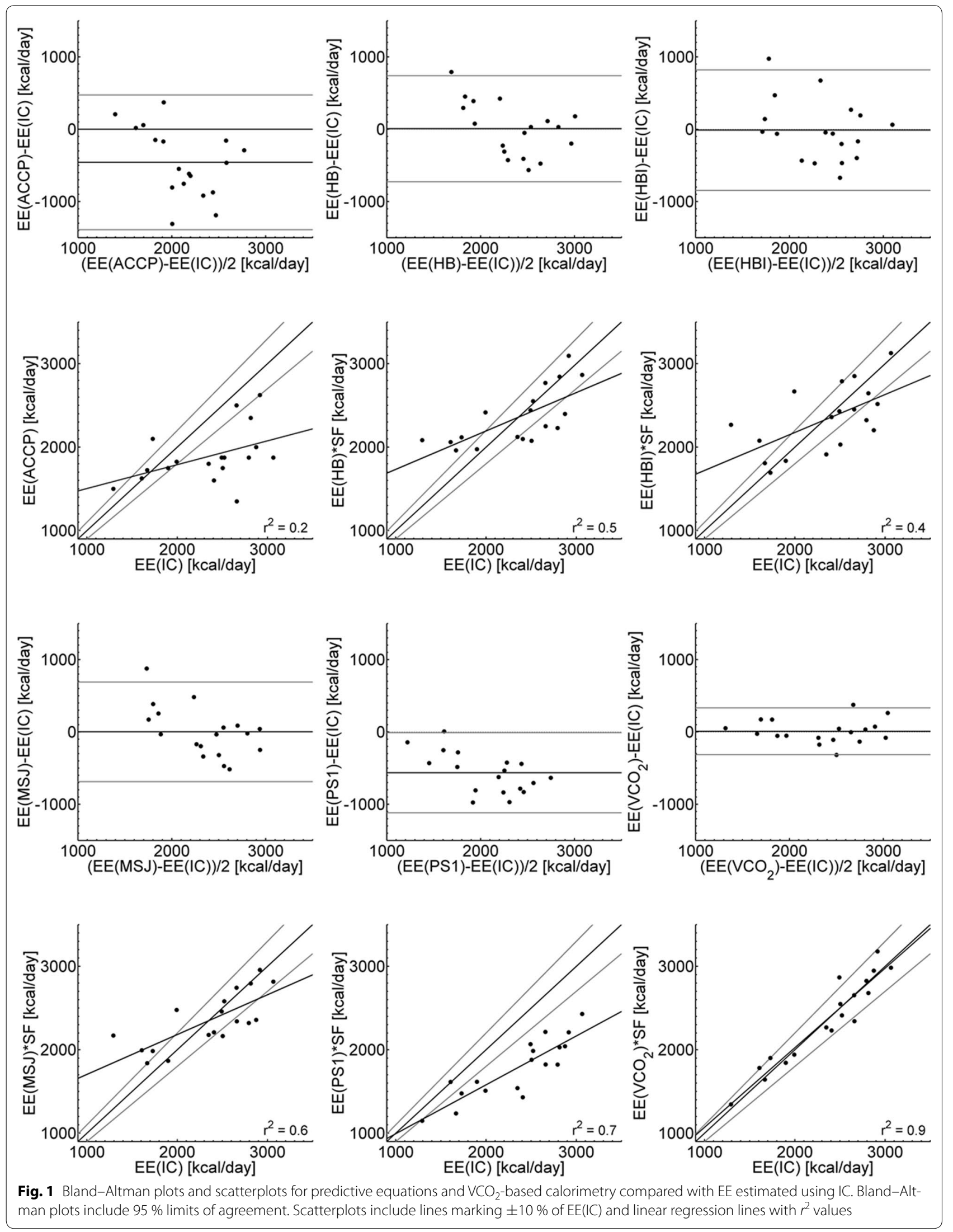




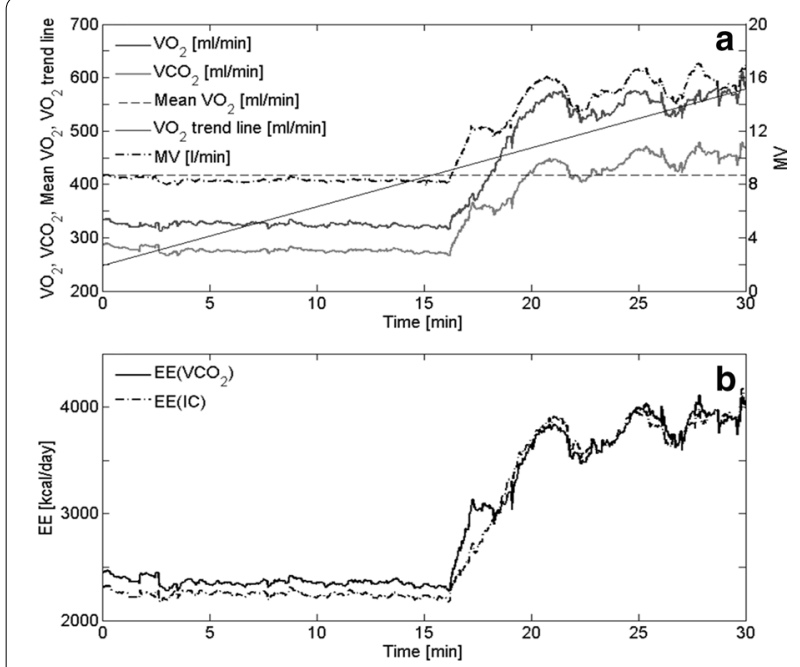

Fig. 2 a Recorded $\mathrm{VO}_{2}, \mathrm{VCO}_{2}$ and $\mathrm{MV}$ from Patient 18. The mean and trend line of $\mathrm{VO}_{2}$ are also displayed. $\mathbf{b} \mathrm{EE}\left(\mathrm{VCO}_{2}\right)$ and $\mathrm{EE}(\mathrm{IC})$ were calculated from recorded $\mathrm{VO}_{2}$ and $\mathrm{VCO}_{2}$

value of $2720 \mathrm{kcal} /$ day. $\mathrm{EE}\left(\mathrm{VCO}_{2}\right)$ remains low, although it increases slowly.

The conclusion on this qualitative analysis is that rapid changes in MV (a rise or fall with a duration of less than $1 \mathrm{~min}$ ) are reflected about equally in $\mathrm{EE}(\mathrm{IC})$ and $\mathrm{EE}\left(\mathrm{VCO}_{2}\right)$, that during maintained changes in $\mathrm{MV}$, $\mathrm{EE}(\mathrm{IC})$ largely recovers within a few minutes and that $\mathrm{EE}\left(\mathrm{VCO}_{2}\right)$ will take $10-20 \mathrm{~min}$ or more to recover.

\section{Quantitative analysis of dynamic errors}

The effect of changes in ventilation is given in Table 4 for each of the 17 patients with stable ventilation. It can be seen that both $\mathrm{EE}(\mathrm{IC})$ and $\mathrm{EE}\left(\mathrm{VCO}_{2}\right)$ are vulnerable to changes in ventilation. $\mathrm{EE}(\mathrm{IC})$ has up to $42 \%$ deviation (Patient 8), and $\mathrm{EE}\left(\mathrm{VCO}_{2}\right)$ has up to $46 \%$ (Patient 16) deviation. $\mathrm{EE}(\mathrm{IC})$ and $\mathrm{EE}\left(\mathrm{VCO}_{2}\right)$ are about equally vulnerable with no significant differences ( $t$ test) between the mean of the max values for the two methods. In clinical practice, this implies that an instantaneous reading of $\mathrm{EE}(\mathrm{IC})$ and $\mathrm{EE}\left(\mathrm{VCO}_{2}\right)$ cannot safely be used to assess EE.

Applying a 5-min moving average to the calculated $\mathrm{EE}(\mathrm{IC})$ reduced the max deviation to $18 \%$ (Table 4, column 3, Patient 10) and the SD of the mean to $7.5 \%$. For $\mathrm{EE}\left(\mathrm{VCO}_{2}\right)$, the max deviation was reduced to $14 \%$ (Table 4 , column 5 , patient 10 ) and the SD of the mean to $7.3 \%$.

This means that the introduction of a 5-min running average reduced the dynamic error of the $\mathrm{EE}\left(\mathrm{VCO}_{2}\right)$ to a size comparable to the RMSE of EE difference (Table 3).

\section{Discussion}

The goal of this study was to investigate the accuracy of $\mathrm{EE}$ estimates by predictive equations and by $\mathrm{VCO}_{2}$-based calorimetry in a small cohort of critically ill patients, most of them soon after admission to the ICU. The results corroborate the previously reported $[6,15]$ inaccuracy of predictive equations for EE. Tatucu-Babet et al. [6] found underestimations of EE up to $41 \%$ and overestimations up to $66 \%$, which is similar to the results in this study. In our study, even the best of the equations, the Mifflin St Jeor equation, was accurate only in $50 \%$ of the patients.

The two predictive equations with the best performance in our study were Mifflin St Jeor and Harris-Benedict. Both of these equations have the methodological problem that they require a SF to account for the increased metabolism following an insult. The SFs giving the best fit to our data were 1.59 and 1.55 for the two equations, respectively. Published mean values for SF for different cohorts range from 1.13 to 1.6 [6], and our cohort values for SF thus fall close to the upper end of the published range. This may partially be due to statistical fluctuations due to our small number of patients, but in general the large range of reported SF implies that SF used must be adapted to the cohort of patients. An additional problem is that EE, and thus SF, tends to increase for the first 9-11 days $[16,17]$ after the insult that led to the admission to the ICU.

In our small sample of ICU patients, $\mathrm{VCO}_{2}$-based calorimetry estimated $\mathrm{EE}$ accurately in most patients (89\%), even in cases where ventilation was changing during the recording period. $\mathrm{VCO}_{2}$-based calorimetry performed significantly better than all predictive equations in agreement with earlier findings both in adults and in children $[21,22]$.

However, $\mathrm{VCO}_{2}$-based calorimetry has two methodological challenges. The first is that the method requires a choice of RQ to be made, and the second is that the accuracy of the estimation is affected by instant variability in measurements of $\mathrm{MV}$ and $\mathrm{VCO}_{2}$.

RQ was fitted to our cohort by choosing the average value of $\mathrm{RQ}$ for the cohort in the calculation of $\mathrm{EE}\left(\mathrm{VCO}_{2}\right)$. In practice, the value of $\mathrm{RQ}$ for the cohort will not be available, and the robustness of $\mathrm{VCO}_{2}$-based calorimetry was explored by a sensitivity analysis. The analysis showed that for any choice of RQ within the published range of cohort values for RQ $(0.76-0.89)$ [14, 18, 32-36], the $\mathrm{EE}\left(\mathrm{VCO}_{2}\right)$ equation performed significantly better than the predictive equations. The results of the sensitivity analysis show that as long as the RQ value chosen by the clinician is within the published range of values, the estimation of EE will be better compared with predictive equations.

The use of nutritional RQ has been explored both in children [21] and in adults [22], and both failed to provide evidence that EE estimates are improved by using 

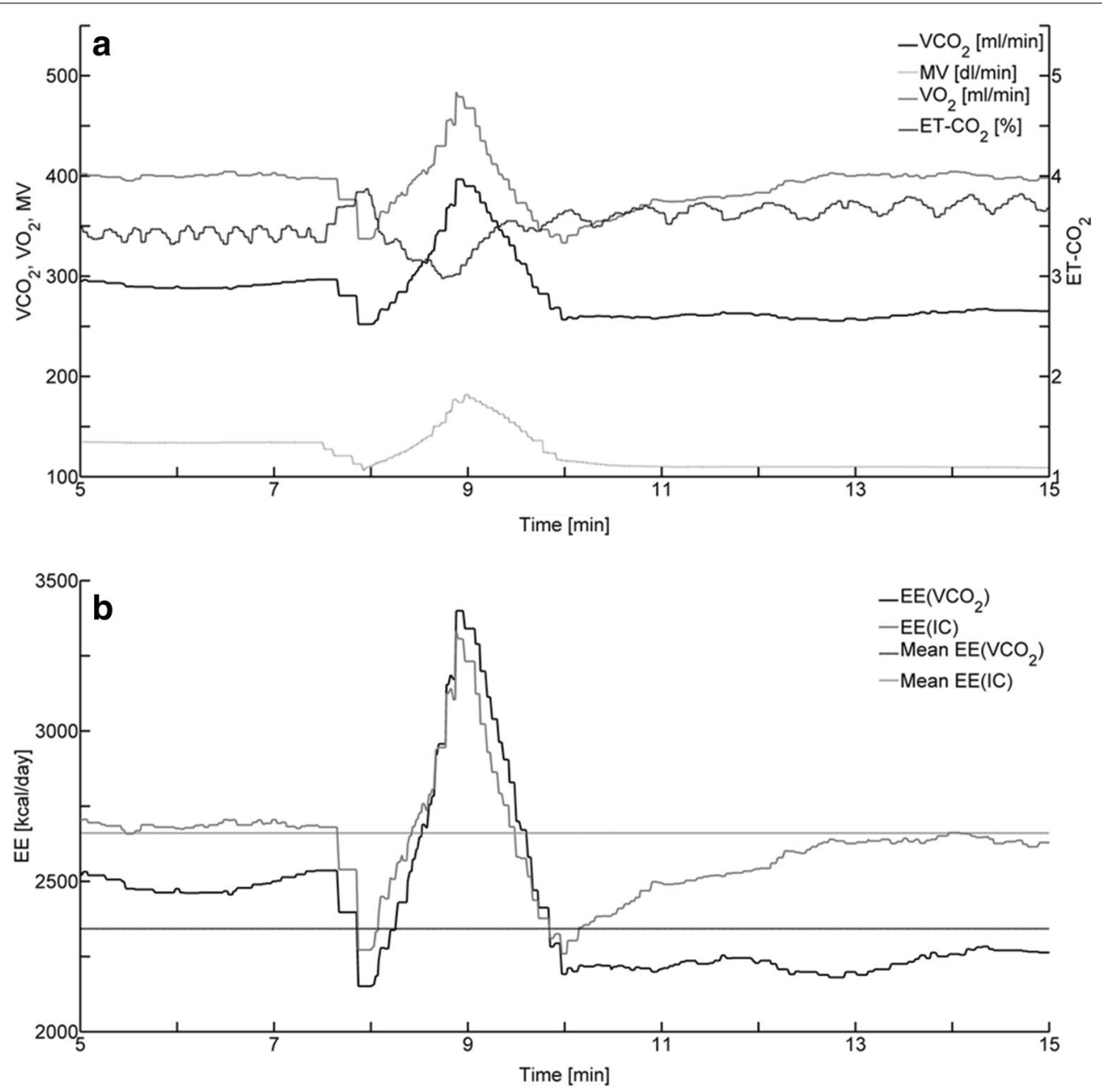

Fig. 3 a Recorded values from Patient 16 of $\mathrm{VCO}_{2}, \mathrm{ET}-\mathrm{CO}_{2}, \mathrm{VO}_{2}$ and $\mathrm{MV}$. b $\mathrm{EE}\left(\mathrm{VCO}_{2}\right)$ and $\mathrm{EE}(\mathrm{IC})$ calculated from recorded $\mathrm{VO}_{2}$ and $\mathrm{VCO}_{2}$, including means of $\mathrm{EE}\left(\mathrm{VCO}_{2}\right)$ and $\mathrm{EE}(\mathrm{IC})$

nutritional RQ. In children [21], the nutritional RQ gave poorer estimates than the mean RQ for the cohort. For the patients in our cohort, a nutrition-based RQ would have given poorer accuracy, as evidenced by the observation that contrary to expectations the patients receiving only glucose had a significantly lower RQ than the patients also receiving enteral nutrition. An explanation of the failure of nutritional RQ to improve EE estimates may be due to the mobilization of the patient's own energy stores in the early catabolic phase of critical illness, where plasma concentrations of glucose, fatty acids and amino acids are strongly increased, thus weakening the link between nutrition and metabolism $[16,17]$.

If a suggestion is to be made on a choice of RQ for $\mathrm{VCO}_{2}$-based calorimetry, the authors suggest 0.85 as this number is in the middle of the physiological range (0.71.0 ); is within the published range of cohort values for
RQ (0.76-0.89); gives an acceptable $-4 \%$ mean EE difference from IC; gives the smallest RMSE (6\%); and is the highest number of accurate EE estimates in this cohort.

The second methodological problem with $\mathrm{VCO}_{2}$-based calorimetry is that $\mathrm{EE}\left(\mathrm{VCO}_{2}\right)$ is inaccurate during and immediately after changes in MV. A qualitative analysis showed that instant values of $\mathrm{EE}$ (IC) were almost as vulnerable to fluctuations in $\mathrm{MV}$ as $\mathrm{EE}\left(\mathrm{VCO}_{2}\right)$ with fluctuations about the same size as the fluctuations in MV. This behavior is compatible with the 10- to 20-min time constant for $\mathrm{VCO}_{2}$ equilibration, supported by both mathematical models of $\mathrm{VCO}_{2}$ storage and transport [28] and experimental data [27]. The problems arising from fluctuations in $\mathrm{MV}$ and thus $\mathrm{VCO}_{2}$ and $\mathrm{VO}_{2}$ are less pronounced when using $\mathrm{IC}$ as the equilibration time for $\mathrm{VO}_{2}$ is $2-3 \mathrm{~min}$, and as can be seen from Eq. (2), $\mathrm{VO}_{2}$ has the larger influence on the EE estimation. Smoothing 
Table 4 Maximal deviations from mean EE and from a mean of EE after the inclusion of a 5-min running average of EE, for both $\mathrm{EE}(\mathrm{IC})$ and $\mathrm{EE}\left(\mathrm{VCO}_{2}\right)$

\begin{tabular}{|c|c|c|c|c|}
\hline & $\begin{array}{l}\text { Max EE(IC) } \\
\text { versus } \\
\mathrm{EE}(\mathrm{IC})(\%)\end{array}$ & $\begin{array}{l}\text { Max } \mathrm{EE}(\mathrm{IC}) \\
\text { versus } \\
\text { 5-min } \mathrm{EE}(\mathrm{IC})(\%)\end{array}$ & $\begin{array}{l}\operatorname{Max} \mathrm{EE}\left(\mathrm{VCO}_{2}\right) \\
\text { versus } \\
\mathrm{EE}\left(\mathrm{VCO}_{2}\right)(\%)\end{array}$ & $\begin{array}{l}\operatorname{Max} \mathrm{EE}\left(\mathrm{VCO}_{2}\right) \\
\text { versus } \\
5 \text {-min } \mathrm{EE}\left(\mathrm{VCO}_{2}\right)(\%)\end{array}$ \\
\hline 1 & -7 & -2 & -11 & -3 \\
\hline 2 & 22 & -12 & -20 & -13 \\
\hline 3 & 12 & -6 & 14 & -5 \\
\hline 4 & -20 & 4 & -21 & 8 \\
\hline 5 & -4 & 1 & -5 & 1 \\
\hline 6 & -4 & -3 & -2 & -1 \\
\hline 7 & 15 & 5 & -7 & 4 \\
\hline 8 & 42 & 11 & -38 & 11 \\
\hline 9 & 11 & 9 & 8 & -6 \\
\hline 10 & 31 & 18 & -24 & 14 \\
\hline 11 & -3 & -1 & 2 & 1 \\
\hline 12 & -6 & -3 & -3 & 2 \\
\hline 13 & 20 & 4 & 5 & 2 \\
\hline 14 & -7 & -2 & -6 & -3 \\
\hline 15 & -9 & 13 & -9 & 11 \\
\hline 16 & -28 & 9 & 46 & 12 \\
\hline 17 & 11 & 4 & 17 & 7 \\
\hline Mean $( \pm S D)$ & $4.4( \pm 18.3)$ & $2.8( \pm 7.5)$ & $-3.2( \pm 18.9)$ & $2.5( \pm 7.3)$ \\
\hline RMS & 18 & 8 & 19 & 8 \\
\hline
\end{tabular}

Deviations are expressed as a percentage of the mean EE

$\mathrm{EE}\left(\mathrm{VCO}_{2}\right)$ and $\mathrm{EE}(\mathrm{IC})$ with a 5 -min running average reduced the sensitivity to fluctuations in $\mathrm{MV}$ and reduced the RMSE of the maximum deviations from 19 and $18 \%$, respectively, to $8 \%$ for both of them. Although a 5 -min average thus substantially reduced the variability of $\mathrm{EE}\left(\mathrm{VCO}_{2}\right)$ and $\mathrm{EE}(\mathrm{IC})$, it is still advisable to avoid using measurements taken during fluctuations or up to $20 \mathrm{~min}$ after changes in MV to allow for equilibration of $\mathrm{VCO}_{2}$. Alternatively 24-h measurements of $\mathrm{VCO}_{2}$ could be used in the $\mathrm{VCO}_{2}$-based calorimetry. Using the mean 24-h value has benefits over a 30 -min measurement period as the influence of fluctuations from hypo- or hyperventilation on $\mathrm{EE}\left(\mathrm{VCO}_{2}\right)$ and $\mathrm{EE}(\mathrm{IC})$ is eliminated, reducing the discrepancy between metabolic production and pulmonary uptake or excretion.

The widespread availability and relatively low cost of capnometers, and software to analyze $\mathrm{VCO}_{2}$ from $\mathrm{CO}_{2}$ concentrations and expiratory volume, may make $\mathrm{VCO}_{2}-$ based calorimetry a simple and accurate method for determination of EE in critically ill patients, whenever needed. Production of the most extensively used IC system (Deltatrac Metabolic Monitor) has been discontinued, and newer available IC systems give conflicting EE estimates [37]. Thus, in the absence of other devices validated for use in the $\mathrm{ICU}$, use of $\mathrm{CO}_{2}$-based calorimetry can represent a useful alternative for the determination of EE.

\section{Abbreviations}

EE: energy expenditure; $\mathrm{VO}_{2}$ : measured oxygen consumption; $\mathrm{VCO}_{2}$ : measured carbon dioxide production; IC: indirect calorimetry; BM: body mass; $\mathrm{MV}$ : minute volume; SF: stress factor; RQ: respiratory quotient; N: nitrogen metabolism.

\section{Authors' contributions}

MHH-P, SA and J-CP contributed to conception and design of the research; $\mathrm{MHH}-\mathrm{P}$ and J-CP contributed to the acquisition of the data; all authors contributed to the analysis and interpretation of the data and drafting of the manuscript, critically revised the manuscript and agree to be fully accountable for ensuring the integrity and accuracy of the work. All authors read and approved the final manuscript.

\section{Author details}

${ }^{1}$ Center for Model-based Medical Decision Support (MMDS), Department of Health Science and Technology, Aalborg University, Fredrik Bajers Vej 7E, 9220 Aalborg East, Denmark. ${ }^{2}$ Department of Intensive Care, Erasme University Hospital, Université Libre de Bruxelles, 808 Route de Lennik, 1070 Brussels, Belgium.

\section{Competing interests}

The study was funded by the respective institutions of the authors, without external financial support, and the authors declare that they have no competing interests.

Received: 28 October 2015 Accepted: 8 February 2016

Published online: 18 February 2016 


\section{References}

1. Fraipont V, Preiser JC. Energy estimation and measurement in critically ill patients. J Parenter Enteral Nutr. 2013;37(6):705-13.

2. Preiser JC, van Zanten AR, Berger MM, Biolo G, Casaer MP, Doig GS, et al. Metabolic and nutritional support of critically ill patients: consensus and controversies. Crit Care. 2015;19(1):35.

3. Weir JdV. New methods for calculating metabolic rate with special reference to protein metabolism. J Physiol (Lond). 1949;109(1-2):1-9.

4. Davis KA, Kinn T, Esposito TJ, Reed RL 2nd, Santaniello JM, Luchette FA. Nutritional gain versus financial gain: the role of metabolic carts in the surgical ICU. J Trauma. 2006;61(6):1436-40.

5. Cheng C, Chen C, Wong Y, Lee B, Kan M, Huang Y. Measured versus estimated energy expenditure in mechanically ventilated critically ill patients. Clin Nutr. 2002;21(2):165-72.

6. Tatucu-Babet OA, Ridley EJ, Tierney AC. The prevalence of underprescription or overprescription of energy needs in critically ill mechanically ventilated adults as determined by indirect calorimetry: a systematic literature review. J Parenter Enteral Nutr. 2016;40(2):212-25.

7. Heidegger CP, Berger MM, Graf S, Zingg W, Darmon P, Costanza MC, et al. Optimisation of energy provision with supplemental parenteral nutrition in critically ill patients: a randomised controlled clinical trial. Lancet. 2013;381 (9864):385-93.

8. Cerra FB, Benitez MR, Blackburn GL, Irwin RS, Jeejeebhoy K, Katz DP, et al. Applied nutrition in ICU patients: a consensus statement of the American College of Chest Physicians. CHEST J. 1997;111(3):769-78.

9. Kreymann KG, Berger MM, Deutz NE, Hiesmayr M, Jolliet P, Kazandjiev $G$, et al. ESPEN guidelines on enteral nutrition: intensive care. Clin Nutr. 2006;25:210-23.

10. Heyland DK, Dhaliwal R, Drover JW, Gramlich L, Dodek P, Canadian Critical Care Clinical Practice Guidelines Committee. Canadian clinical practice guidelines for nutrition support in mechanically ventilated, critically ill adult patients. J Parenter Enteral Nutr. 2003;27(5):355-73.

11. Harris JA, Benedict FG. A biometric study of human basal metabolism. Proc Natl Acad Sci USA. 1918;4(12):370-3.

12. Mifflin MD, St Jeor ST, Hill LA, Scott BJ, Daugherty SA, Koh YO. A new predictive equation for resting energy expenditure in healthy individuals. Am J Clin Nutr. 1990;51(2):241-7.

13. Frankenfield D. Energy dynamics. In: LE Matarese GM, editor. Contemporary nutrition support practice: a clinical guide Philadelphia. Philadelphia: W.B. Saunders Company; 1998. p. 79-98.

14. Frankenfield D, Smith JS, Cooney RN. Validation of 2 approaches to predicting resting metabolic rate in critically ill patients. J Parenter Enteral Nutr. 2004;28(4):259-64.

15. Frankenfield D, Roth-Yousey L, Compher C, Evidence Analysis Working Group. Comparison of predictive equations for resting metabolic rate in healthy nonobese and obese adults: a systematic review. J Am Diet Assoc. 2005;105(5):775-89.

16. Plank LD, Hill GL. Sequential metabolic changes following induction of systemic inflammatory response in patients with severe sepsis or major blunt trauma. World J Surg. 2000;24:630-8.

17. Monk DN, Plank LD, Franch-Arcas G, Finn PJ, Streat SJ, Hill GL. Sequential changes in the metabolic response in critically injured patients during the first 25 days after blunt trauma. Ann Surg. 1996;223(4):395-405.

18. Dickerson RN, Gervasio JM, Riley ML, Murrell JE, Hickerson WL, Kudsk $K A$, et al. Accuracy of predictive methods to estimate resting energy expenditure of thermally-injured patients. J Parenter Enteral Nutr. 2002;26(1):17-29.

19. Ortega R, Connor C, Kim S, Djang R, Patel K. Monitoring ventilation with capnography. N Engl J Med. 2012;367(19):e27.

20. Rousing ML, Simonsen M, Andreassen S, Pielmeier U, Preiser J. Comparison of resting energy expenditure estimated using predictive equations and measured using indirect calorimetry in critically ill patients. Intensive Care Med. 2014;40(Supplement 1):82.

21. Mehta NM, Smallwood CD, Joosten KF, Hulst JM, Tasker RC, Duggan CP. Accuracy of a simplified equation for energy expenditure based on bedside volumetric carbon dioxide elimination measurement-a two-center study. Clin Nutr. 2015;34(1):151-5.

22. Stapel SN, de Grooth HS, Alimohamad H, Elbers PWG, Girbes ARJ, Weijs PJM, et al. Ventilator-derived carbon dioxide production to assess energy expenditure in critically ill patients: proof of concept. Crit Care. 2015;19:370.

23. McClave SA, Lowen CC, Kleber MJ, McConnell JW, Jung LY, Goldsmith LJ. Clinical use of the respiratory quotient obtained from indirect calorimetry. J Parenter Enteral Nutr. 2003;27(1):21-6.

24. Knaus WA, Draper EA, Wagner DP, Zimmerman JE. APACHE II: a severity of disease classification system. Crit Care Med. 1985;13(10):818-29.

25. Masuda T, Kuramoto M, Tanimoto H, Yamamoto K, Ikeshima S, Kitano Y, et al. Intraoperative baseline oxygen consumption as a prognostic factor in emergency open abdominal surgery. J Crit Care. 2015. doi:10.1016/j. jcrc.2015.11.014.

26. GE Healthcare. Datex-Ohmeda S/5-modules technical reference manual. 2005.

27. Ivanov S, Nunn J. Influence of duration of hyperventilation on rise time of P CO2, after step reduction of ventilation. Respir Physiol. 1968;5(2):243-9.

28. Andreassen S, Rees SE. Mathematical models of oxygen and carbon dioxide storage and transport: interstitial fluid and tissue stores and whole-body transport. Crit Rev Biomed Eng. 2005;33(3):265-98.

29. Chiumello D, Coppola S, Froio S, Mietto C, Brazzi L, Carlesso E, et al. Time to reach a new steady state after changes of positive end expiratory pressure. Intensive Care Med. 2013;39(8):1377-85.

30. McClave SA, Martindale RG, Vanek VW, McCarthy M, Roberts P, Taylor B, et al. Guidelines for the provision and assessment of nutrition support therapy in the adult critically ill patient: Society of Critical Care Medicine (SCCM) and American Society for Parenteral and Enteral Nutrition (ASPEN). J Parenter Enteral Nutr. 2009;33(3):277-316.

31. Hamwi G. Therapy: changing dietary concepts. In: Danowski T, editor. Diabetes mellitus: diagnosis and treatment, vol. 1. American Diabetes Association; 1964. p. 73-8.

32. Weissman C, Kemper M. CRTT tJA. Resting metabolic rate of the critically ill patient: measured versus predicted. Anesthesiology. 1986;64(6):673-9.

33. Weissman C, Kemper M, Elwyn D, Askanazi J, Hyman A, Kinney J. The energy expenditure of the mechanically ventilated critically ill patient. An analysis. CHEST J. 1986;89(2):254-9.

34. Faisy C, Guerot E, Diehl JL, Labrousse J, Fagon JY. Assessment of resting energy expenditure in mechanically ventilated patients. Am J Clin Nutr. 2003;78(2):241-9.

35. Hanique G, Dugernier T, Laterre P, Dougnac A, Roeseler J, Reynaert M. Significance of pathologic oxygen supply dependency in critically ill patients: comparison between measured and calculated methods. Intensive Care Med. 1994;20(1):12-8.

36. Bursztein $S$, Saphar $P$, Singer $P$, Elwyn DH. A mathematical analysis of indirect calorimetry measurements in acutely ill patients. Am J Clin Nutr. 1989;50(2):227-30.

37. Sundström M, Tjäder I, Rooyackers $\mathrm{O}$, Wernerman J. Indirect calorimetry in mechanically ventilated patients. A systematic comparison of three instruments. Clin Nutr. 2013;32(1):118-21. 